Journal of Mathematics and Statistics 3 (4): 228-232, 2007

ISSN 1549-3644

C 2007 Science Publications

\title{
Variable Velocity Influence on the Vibration of Simply Supported Bernoulli - Euler Beam Under Exponentially Varying Magnitude Moving Load
}

\author{
Awodola T. O. \\ Department of Mathematical Sciences \\ Federal University of Technology, Akure, Nigeria
}

\begin{abstract}
The variable velocity influence on the vibration of a simply supported Bernoulli-Euler beam, resting on a uniform foundation, under the action of an exponentially varying magnitude load moving with variable velocity is investigated in this work. The technique is based on the Finite Fourier Sine transformation and the Finite Difference method. Numerical results in plotted curves are presented. It is observed from the plotted curves that, when the foundation modulli ' $\mathrm{K}$ ' and the axial force ' $\mathrm{N}$ ' are fixed, the transverse deflections of the beam under load moving with variable velocity are higher than the deflections when the load moves with constant velocity. It is also observed that the response amplitudes in both cases of variable velocity and constant velocity decrease both with increasing ' $\mathrm{K}$ ' and with increasing ' $\mathrm{N}$ '. Also, the analysis shows that the effects of the foundation modulli ' $\mathrm{K}$ ' and the axial force ' $\mathrm{N}$ ' are more pronounced in the vibration of the beam under load moving with variable velocity than in the case when the load moves with constant velocity, hence more reinforcement is needed when the load moves with variable velocity.
\end{abstract}

Keywords: Bernoulli-Euler, foundation modulli

\section{INTRODUCTION}

When loads move on solid bodies, they cause them to vibrate. Investigators have concerned themselves with the study of such elastic bodies under the influence of moving loads. As a result, various investigations have been carried out on this subject. Willis et al ${ }^{[1]}$ considered the problem of elastic beam under the action of moving loads. In this study, the mass of the beam was considered much smaller than the mass of the moving load.

Timoshenko ${ }^{[2]}$ later considered the problem of simply supported finite beams lying on an elastic foundation and traversed by moving loads. In his analysis he assumed that the loads were moving with constant velocities along the beam. Oni ${ }^{[3]}$ considered the response of a thick beam under the action of harmonic variable concentrated force moving at a uniform velocity. The method of integral transformation was used, in particular, the finite transform (Fourier) is used for length co-ordinate and the Laplace transform for the time co-ordinate. Solution, which converges, was obtained for the deflection of simply supported thick beam. The effect of an elastic foundation on the transverse displacement of the beam was analyzed for the problem.

Kenny ${ }^{[4]}$ investigated the dynamic response of finite elastic beam under the influence of a dynamic load moving with constant speed. Awodola ${ }^{[5]}$ analyzed the influence of foundation and axial force on the vibration of thin beam under variable harmonic moving load.

However, the above studies failed to give the effect of variable velocity on the transverse displacement of a thin beam subjected to moving loads. Thus, this work is set to investigate the influence of variable velocity, foundation modulli and axial force on the transverse deflection of a thin beam (Bernoulli-Euler beam) subjected to a load of exponentially varying magnitude and moving with variable velocity.

\section{MATERIALS AND METHODS}

The governing equation: The equation of motion of a thin beam undergoing transverse vibration due to a moving load is derived using Newton's second law of motion. Let us consider a beam resting on an elastic foundation $(\mathrm{k})$ under moving load $\mathrm{P}(\mathrm{x}, \mathrm{t})$, subjected to an axial force $\mathrm{N}$, which remains parallel to the $\mathrm{x}$-axis. A portion of the beam is shown in figure 1 below.

Corresponding Author: Awodola Thomas Olubunmi, Department of Mathematical Sciences, Federal University of Technology, Akure, Nigeria 


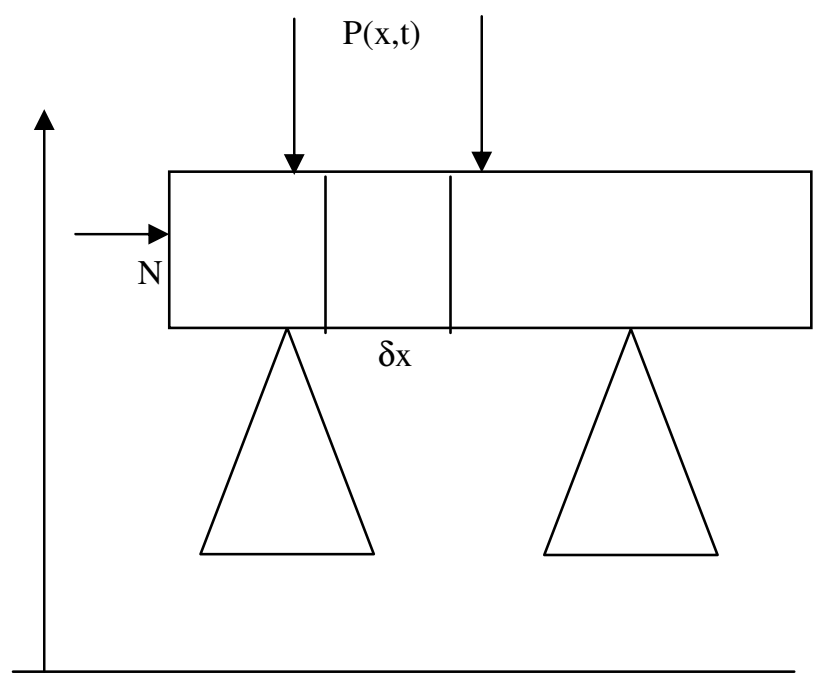

Fig. 1: A portion of a beam

$\mathbf{X}$

The differential equation for the deflection of the Bernoulli-Euler beam under a moving load when the beam is of constant flexural rigidity EI and supported by the elastic foundation constant ' $\mathrm{K}$ ' is given by:

$$
\begin{aligned}
& E I \frac{\partial^{4} v(x, t)}{\partial x^{4}}+\frac{\mu \partial^{2} v(x, t)}{\partial t^{2}}-N \frac{\partial^{2} v(x, t)}{\partial x^{2}} \\
& +2 \mu W_{b} \frac{\partial v(x, t)}{\partial t}+K v(x, t)=P(x, t)
\end{aligned}
$$

where

$\mathrm{E}=$ Young modulus

$\mathrm{I}=$ Moment of inertial of the cross section

$\mu=$ Mass per unit length of the beam

$\mathrm{W}_{\mathrm{b}}=$ circular frequency of the beam

$\mathrm{N}=$ axial force

$\mathrm{V}(\mathrm{x}, \mathrm{t})=$ Transverse displacement

$\mathrm{x}=$ spatial co-ordinate

\section{$\mathrm{t}=$ Time co-ordinate}

$\mathrm{K}=$ Elastic foundation constant

$\mathrm{P}(\mathrm{x}, \mathrm{t})=$ Impressed force.

Equation (2.1) is the equation of motion for the transverse vibration of thin beam under moving loads with the following assumptions

(i) The transverse shear deformation is neglected.

(ii) The beam is of uniform cross-section and constant mass per unit length.

(iii) There is an axis of the beam that undergoes no extension or contraction. The x-axis is located along the neutral axis. (iv) The $x-y$ plane is the principal plane.

(v) The beam is simply supported at both edges.

In this paper, the beam model, taken to be simply supported, has the boundary conditions taking the form;

$$
\begin{aligned}
& \mathrm{v}(0, \mathrm{t})=\mathrm{v}(\mathrm{L}, \mathrm{t})=0 \\
& \frac{\partial^{2} v(0, t)}{\partial x^{2}}=\frac{\partial^{2} v(l, t)}{\partial x^{2}}=0
\end{aligned}
$$

with the initial conditions, for simplicity, taken to be

$\mathrm{v}(\mathrm{x}, 0)=0=\frac{\partial v(x, 0)}{\partial t}$

We shall consider the load moving on the elastic beam model and investigate the influence of variable velocity on the deflection of the beam under a load moving with variable velocity. We shall adopt the example in [5] and take the moving load to be of the form;

$\mathrm{P}(\mathrm{x}, \mathrm{t})=\mathrm{P}(\mathrm{t}) \delta\left[\mathrm{x}-\left(\mathrm{x}_{0}+\beta \sin \alpha \mathrm{t}\right)\right]$ for load moving with variable velocity. and

$$
\mathrm{P}(\mathrm{x}, \mathrm{t})=\mathrm{P}(\mathrm{t}) \delta[\mathrm{x}-\mathrm{ct}]
$$

for load moving with constant velocity where $\mathrm{P}(\mathrm{t})$ is the variable magnitude of the load, sinat is the distance function which makes the velocity of the moving load a variable, $\mathrm{c}$ is the constant velocity and $\mathrm{x}_{0}, \beta$ and $\alpha$ are constants.

The function $\delta(\mathrm{x})$ is defined as:

$$
\delta(x)=\left\{\begin{array}{l}
0 ; x \neq 0 \\
\infty ; x=0
\end{array}\right.
$$

and is called the dirac-delta function with the property;

$$
\int_{a}^{b} \delta(x-k) f(x) d x= \begin{cases}f(k) ; & a<k<b \\ 0 ; & a<b<k \\ 0 ; & k<a<b\end{cases}
$$

For an exponentially varying magnitude load, $\mathrm{P}(\mathrm{t})$ is chosen to be of the form $\mathrm{P}(\mathrm{t})=\mathrm{Pe}^{\mathrm{t}}$. (2.5a) then becomes;

$$
\mathrm{P}(\mathrm{x}, \mathrm{t})=\mathrm{Pe}^{\mathrm{t}} \delta\left[\mathrm{x}-\left(\mathrm{x}_{0}+\beta \sin \alpha \mathrm{t}\right)\right]
$$

Substituting equation (2.8) into equation (2.1) we have;

$$
\begin{aligned}
& E I \frac{\partial^{4} v(x, t)}{\partial x^{4}}+\frac{\mu \partial^{2} v(x, t)}{\partial t^{2}}-\frac{N \partial^{2} v(x, t)}{\partial x^{2}} \\
& +\frac{2 \mu W_{b} \partial v(x, t)}{\partial t}+k V(x, t) \\
& =P e^{t} \delta\left[x-\left(x_{0}+\beta \sin \alpha t\right)\right]
\end{aligned}
$$


Method of solution: The governing equation (2.9) above is a fourth order non -homogenous partial differential equation with variable co-efficients. To obtain the solution to the differential equation (2.9), use is made of the Finite Fourier sine transform given by.

$$
V(m, t)=\int_{0}^{L} V(x, t) \sin \frac{m \pi x}{L} d x
$$

With the inverse

$$
V(x, t)=\frac{2}{L} \sum_{m=1}^{\infty} V(m, t) \sin \frac{m \pi x}{L}
$$

Using the transformation (3.1) in (2.9), applying the property of the dirac-delta function given in equation (2.7) in conjunction with the boundary conditions (2.2) and (2.3), one obtains

$$
\begin{aligned}
& E\left(\frac{m \pi}{L}\right)^{4} v(m, t)+N\left(\frac{m \pi}{L}\right)^{2} v(m, t)+\frac{\mu \partial^{2} v(m, t)}{\partial t^{2}} \\
& +2 \mu W_{b} \frac{\partial v(m, t)}{\partial t}+k v(m, t) \\
& =P e^{t} \sin \left[\frac{m \pi\left(X_{0}+\beta \sin \alpha t\right)}{L}\right]
\end{aligned}
$$

Equation (3.3) after some rearrangements gives

$$
\begin{aligned}
& \frac{\partial^{2} v(m, t)}{\partial t^{2}}+\frac{H_{0} \partial v(m, t)}{\partial t}+H_{5} V(m, t) \\
& =H_{4} e^{t} \sin \frac{m \pi\left(X_{0}+\beta \sin \alpha t\right)}{L}
\end{aligned}
$$

Where $\mathrm{H}_{0}=2 \mathrm{~W}_{\mathrm{b}}, \mathrm{H}_{5}=\mathrm{H}_{1}+\mathrm{H}_{2}+\mathrm{H}_{3}$

$$
\begin{aligned}
& H_{1}=\frac{E I}{\mu}\left[\frac{m \pi}{L}\right]^{4}, H_{2}=\frac{N}{\mu}\left[\frac{m \pi}{L}\right]^{2}, \\
& H_{3}=\frac{k}{\mu}, H_{4}=\frac{P}{\mu}
\end{aligned}
$$

Thus the problem reduces to solving the second order differential equation (3.4).

To solve the equation (3.4) we use the finite difference method defined by

$$
\frac{\partial^{2} v(m, t)}{\partial t^{2}}=\frac{V_{j+1}-2 V_{j}+V_{j-1}}{h^{2}}
$$

and

$$
\frac{\partial v(m, t)}{\partial t}=\frac{V_{j+1}-V_{j-1}}{2 h}
$$

Where $\mathrm{h}$ is the mesh size

Substituting (3.5) and (3.6) into (3.4) we have;

$$
\begin{aligned}
& \frac{V_{j+1}-2 V_{j}+V_{j-1}}{h^{2}}+H_{0}\left[\frac{V_{j+1}-V_{j-1}}{2 h}\right] \\
& +V_{j} H_{5}=H_{4} e^{t} \frac{\sin m \pi\left(X_{0}+\beta \sin \alpha t\right)}{L}
\end{aligned}
$$

Equation (3.7), upon rearrangement, gives

$$
\begin{array}{r}
V_{j+1}=\frac{1}{2+}+h H_{0}\left[2 h^{2} H_{4} e^{t} \sin \frac{m \pi\left(X_{0}+\beta \sin \alpha\right)}{L}\right. \\
\left.\quad-V_{j-1}\left(2-h H_{0}\right)-V_{j}\left(2 h^{2} H_{5}-4\right)-\right]
\end{array}
$$

Hence in view of equation (3.2) one obtains

$$
\begin{aligned}
V(x, t) & =\frac{2}{L} \sum_{m=1}^{\infty}\left\{\frac { 1 } { 2 + h H _ { 0 } } \left[2 h^{2} H_{4} e^{t} \sin \frac{m \pi\left(X_{0}+\beta \sin o t\right)}{L}\right.\right. \\
& \left.-V_{j-1}\left(2-h H_{0}\right)-V_{j}\left[2 h^{2} H_{5}-4\right]-\right\} \frac{\sin m \pi x}{L}
\end{aligned}
$$

Equation (3.9) is the transverse displacement response of the thin (Bernoulli-Euler) beam subjected to exponentially varying magnitude load moving with variable velocity.

\section{RESULTS AND DISCUSSION}

An elastic beam of length $12.123 \mathrm{~m}$ has been considered. The values of foundation modulli ' $\mathrm{K}$ ' are ranged between $0 \mathrm{~N} / \mathrm{m}^{3}$ and $5,000,000 \mathrm{~N} / \mathrm{m}^{3}$ and values of axial force varies between $0 \mathrm{~N}$ and $10,000,000 \mathrm{~N}$. Furthermore, the constant flexural rigidity 'EI' is taken to be $6.068 \times 10^{6} \mathrm{~m}^{3} / \mathrm{s}^{2}$. The results are displayed graphically in the figures 4.01 to 4.05 .

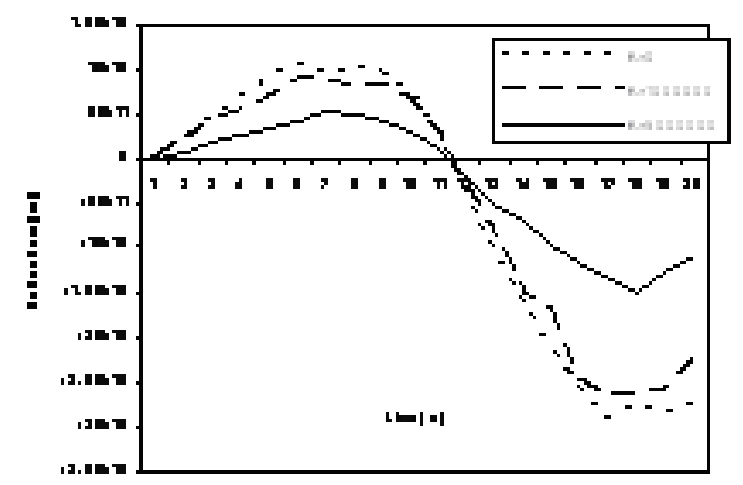

Fig. 4.01: Deflection profile of Bernoulli- Euler beam under load moving with variable velocity for various values of foundation modulli ' $\mathrm{K}$ ' 


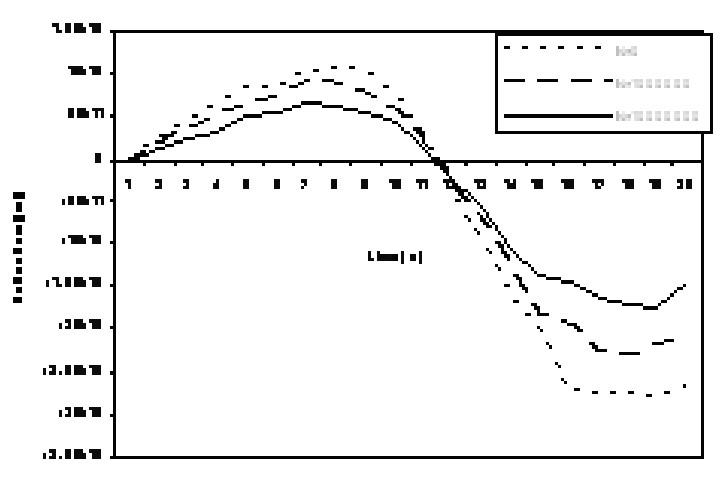

Fig. 4.02: Deflection profile of Bernoulli- Euler beam under load moving with variable velocity for various values of axial force ' $\mathrm{N}$ '

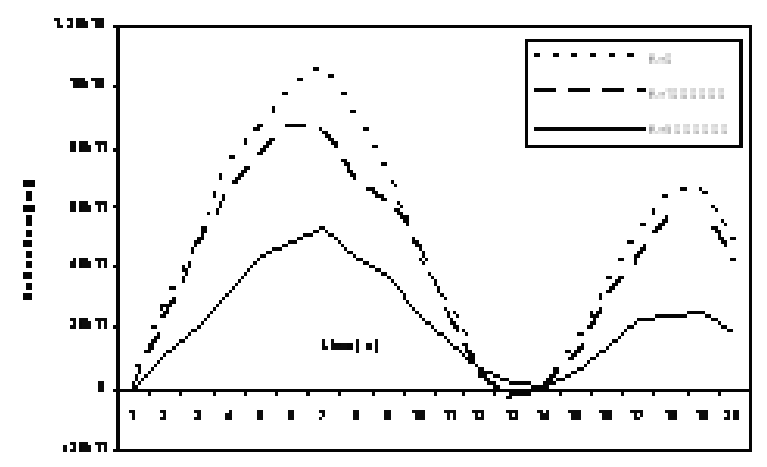

Fig. 4.03: Deflection profile of Bernoulli- Euler beam under load moving with constant velocity for various values of foundation modulli ' $\mathrm{K}$ '

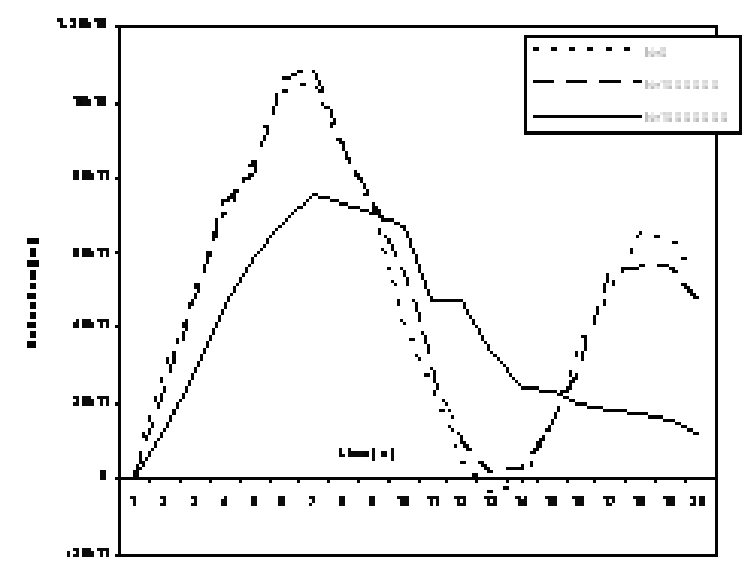

Fig. 4.04: Deflection profile of Bernoulli- Euler beam under load moving with constant velocity for various values of axial force ' $\mathrm{N}$ '

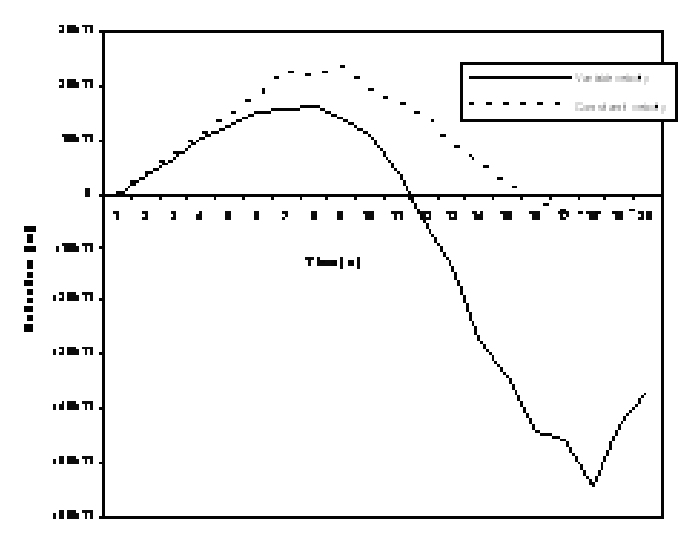

Fig. 4.05: Comparison of deflection due to load moving with variable velocity and that due to load moving with constant velocity.

Figs 4.01 and 4.02 show the deflection of simply supported Bernoulli-Euler beam under the action of exponentially varying magnitude load moving with variable velocity for various values of foundation modulli ' $\mathrm{K}$ ' and axial force ' $\mathrm{N}$ ' respectively. While figures 4.03 and 4.04 display the displacement response of the same beam under the same load but moving with constant velocity for various values of $\mathrm{K}$ and $\mathrm{N}$ respectively. It is shown that as $\mathrm{F}$ increases, the displacement response decreases for both cases of variable and constant velocities. The same result obtains as $\mathrm{N}$ increases

For the purpose of comparison the displacement curves for both cases of variable velocity and constant velocity with fixed $\mathrm{K}$ and $\mathrm{N}$ are illustrated in figure 4.05. It can be noted that the response amplitude for the case of variable velocity is greater than that for the case of constant velocity. This result holds for any choice of values of $\mathrm{K}$ and $\mathrm{N}$. This shows that it could be tragic to use the reinforcement meant for the beam under load moving with constant velocity to maintain the beam under the load when it moves with variable velocity.

\section{CONCLUSION}

The influence of axial force, foundation modulli and variable velocity on the transverse deflection of a thin beam under the action of load moving with variable velocity has been investigated. The beams are assumed to rest on uniform constant foundation and the moving loads are assumed to be concentrated forces (loads). 
The beam problem is solved and the deflections for various values of the axial force $(\mathrm{N})$ and foundation modulli (K) were obtained and plotted against time $(\mathrm{T})$ for both cases when the load moves with constant velocity and when it moves with variable velocity. It was found that the amplitude of vibration decreases with increase in the values of axial force and foundation modulli for both cases of constant and variable velocities. It was also shown that the response amplitude for the case of variable velocity is greater than that for the case of constant velocity. Therefore, more reinforcement than that meant for the beam under load moving with constant velocity is needed to maintain the beam under the load when it moves with variable velocity.

This study is of paramount importance to field engineers in the construction of bridges, railway, cranes etc. There is the need to know the strength of materials required for construction.

\section{ACKNOWLEDGEMENTS}

I would like to acknowledge my $\mathrm{PhD}$ supervisor, Professor S. T. Oni of the Department of Mathematical Sciences, Federal University of Technology, Akure, Nigeria, who gave me the necessary training for such a research work as this.

\section{REFERENCES}

1. Willis, R. et al. 1951. Preliminary essay to the appendix B. Experiment to determine the effects produced by causing weights to travel over bars with different velocities Barlow P., Treatise on the strength of timber, cast iron and malleable iron. London

2. Timoshenko, S. 1922. On the transverse vibrations of bars of uniform cross-section. Philosophy Mag. Ser. 6, Vol. 43, pp. $125-131$

3. Oni, S.T. 1990. On thick beams under the action of a variable traveling transverse load. Abacus Journal of Mathematical Association of Nigeria

4. Kenny, J. 1954. Steady State vibrations of a beam on an elastic foundation for a moving load. Journal of applied mechanic (ASME), vol.76 pp 369-364

5. Awodola, T.O. 2005. Influence of foundation and axial force on the vibration of thin beam under variable harmonic moving load. Journal of the Nigerian Association of Mathematical Physics (JNAMP), vol. 9. Pp 143 - 150. 